\title{
IMPLIKATUR NON-KONVENSIONAL PADA NOVEL 5 CM KARYA DONY DIRGANTARA
}

\author{
Windo Dicky Irawan ${ }^{1}$, Herwin $^{2}$ \\ ${ }^{1,2)}$ FKIP Universitas Muhammadiyah Kotabumi
}

\begin{abstract}
This research on non-conventional Implications is based on the $5 \mathrm{~cm}$ Novel by Donny Dirgantara. A literary work can be researched, enjoyed, and lived in, as well as studies related to real-life images used by the author. Readers can look for implicit meanings, or something different from what the speaker actually says. Therefore, the aim of this study is to look at the conversations of the characters in Donny Dhirgantoro's $5 \mathrm{~cm}$ novel non-conventional. The method used in this research is descriptive method through a qualitative approach. Based on the results of the research, there are twelve non-conventional data that have the meaning of meaning, namely wanting to imply something with the truth.
\end{abstract}

Keywords: Non-Conventional Implications, Literature Work, Novel

Abstrak: Penelitian implikatur non-konvensional ini bersumber dari Novel $5 \mathrm{~cm}$ karya Donny Dirgantara. Sebuah karya sastra dapat diteliti, dinikmati, dan dihayati, serta sekaligus dimengerti oleh pembaca terkait gambaran kehidupan nyata yang digunakan penulis. Pembaca dapat mencari maksud-maksud yang implisit, atau sesuatu yang berbeda dengan yang sebenarnya diucapkan oleh penutur. Oleh karena itu, tujuan penelitian ini untuk mengetahui implikatur non-konvensional percakapan tokoh dalam novel $5 \mathrm{~cm}$ Karya Donny Dhirgantoro. Metode yang digunakan dalam penelitian ini adalah metode deskriptif melalui pendekatan kualitatif. Berdasarkan hasil penelitian ini, terdapat dua belas data implikatur non-konvensional yang bertujuan menyiratkan sesuatu dengan yang sebenarnya.

Kata Kunci: Implikatur Non-Konvensional, Karya Sastra, Novel

\section{PENDAHULUAN}

Bahasa merupakan alat komunikasi yang memegang peranan sangat penting bagi kehidupan manusia, karena bahasa merupakan alat untuk berinteraksi dan berkomunikasi serta berhubungan sosial. Oleh karena itu, bahasa berfungsi sebagai alat berkomunikasi antar anggota masyarakat.

${ }^{1}$ Dosen Universitas Muhammadiyah Kotabumi

${ }^{2}$ Mahasiswa Universitas Muhammadiyah Kotabumi
Bahasa sebagai alat komunikasi antar masyarakat dalam penyampaian pesan, baik secara lisan maupun tulis. Bahasa lisan yang dipakai dalam percakapan antar anggota masyarakat itu terkadang tidak dapat dipahami melalui teks kalimat yang disampaikan oleh penutur saja, tetapi harus menghubungkan pada konteks lainnya. Terlebih lagi ketika seseorang berbicara 
kepada yang lebih tua, harus menggunakan kata sapaan dan bahasa yang lebih halus. Kata sapaan itu berfungsi untuk menyapa, menegur seseorang, bahkan menyebut orang kedua, atau orang yang diajak berbicara (Irawan, 2019:96). Kajian semacam itu di lingkunngan linguistik dikenal dengan kajian pragmatik.

Pragmatik dalam kajian semantik adalah menguraikan aspek-aspek makna yang tidak dapat ditemukan dalam pengertian kata atau struktur yang harus dikaitkan dengan konteks. Menurut Rusminto (2010:16) pemakaian bahasa, baik tulis maupun lisan berkaitan dengan pragmatik yang dalam situasi penggunaan bahasa sesungguhnya. Oleh karena itu, kajian pragmatik dalam penggunaan bahasa harus melihat konteks yang seutuhnya.

Konteks seutuhnya itu dimengerti jika percakapan antar masyarakat memiliki pemahaman latar belakang yang sama. Percakapan antar anggota masyrakat yang terjalin itu membutuhkan pemahaman terhadap makna tuturan baik secara tersirat maupun tersurat. Masyarakat dalam berkomunikasi, biasanya menggunakan makna tersirat yang ungkapannya tidak jelas oleh penutur. Hal itu lazim dikenal dengan istilah Implikatur. Implikatur dapat dibedakan menjadi dua jenis, yaitu implikatur konvensional dan non konvensional (Grice dalam Kuntarto, 2016:33)

Implikatur konvensional merupakan implikatur yang sifatnya umum, sehingga semua orang mengetahui maksud mengenai suatu hal tertentu berdasarkan konvensi yang telah ada. Implikatur non-konvensional lebih menekankan pada ujaran yang menyiratkan sesuatu yang berbeda dengan yang sebenarnya. Implikatur non-konvensional juga merupakan jenis komunikasi percakapan yang menyamarkan makna terhadap lawan tutur agar berbeda dengan yang sebenarnya (Kuntarto, 2016:33). Artinya implikatur ini bersifat tersirat di dalam suatu percakapan.

Contoh:

\section{A: "Jam tanganmu baru tuh? Mengapa}

tidak membeli Kondotti aja?"

B: "Ah, harganya terlalu mahal."

Tuturan di atas memberi gambaran bahwa jam tangan yang dibeli oleh si-B memiliki harga lebih murah dari pada yang ditawarkan oleh si-A. Artinya, dalam komunikasi baik secara tulis maupun lisan tidak mesti sama maknanya karena harus melihat dari situasi atau konteks ujaran.

Konteks ujaran terdapat juga pada sebuah karya sastra, misalnya cerpen atau novel. Pembaca dapat mencari maksudmaksud yang implisit, yang diucapkan oleh 
tokoh pada novel atau cerpen. Oleh karena itu, dari pemaparan tersebut penulis hendak melakukan penelitian untuk mengetahui implikatur percakapan tokoh dalam sebuah karya sastra, yaitu berupa novel. Novel yang dijadikan objek penelitian ini adalah novel $5 \mathrm{~cm}$ karya Donny Dhirgantoro. Tujuan penelitian ini adalah untuk mengetahui implikatur yang ada di dalam novel $5 \mathrm{~cm}$ karya Donny Dhirgantoro.

Berdasarkan dari uraian latar belakang masalah, rumusan masalah dalam penelitian ini adalah bagaimana analisis implikatur dalam novel $5 \mathrm{~cm}$ karya Donny Dhirgantoro?

\section{METODE}

Penelitian ini menggunakan metode deskriptif yang menguraikan berdasarkan fakta-fakta yang menghasilkan paparan seperti apa adanya (Sudaryanto, 2017:62).

Sumber data pada penelitian ini adalah novel yang berjudul $5 \mathrm{~cm}$ karya Donny Dhirgantoro.

Data tersebut dikumpulkan dan dianalisis sesuai rumusan masalah yaitu implikatur non-konvensional. Selanjutnya, dilakukan pendeskripsian dengan paparan yang kualitatif.

\section{HASIL DAN PEMBAHASAN}

\section{Hasil}

Hasil analisis yang ditemukan pada penelitian ini adalah terdapat 12 implikatur non-konvensional.

Tabel 1.1 Implikatur NonKonvensional

\begin{tabular}{|c|c|}
\hline No. & Implikatur NonKonvensional \\
\hline 1 & $\begin{array}{l}\text { "Ada nyokap lo nggak?" Zafran sok basa-basi } \\
\text { "Ada adik gue Lo mau?" jawab Arial. }\end{array}$ \\
\hline 2 & $\begin{array}{l}\text { "Ada yang mau Indomie nggak?" Arial menawari teman- } \\
\text { temannya. } \\
\text { Semua menggeleng kecuali Ian. } \\
\text { "Pake telornya dua yaa...," Ian teriak. }\end{array}$ \\
\hline 3 & $\begin{array}{l}\text { "Kalo dikampus nongkrongnya di mana?" "Nggak } \\
\text { nongkrong." } \\
\text { "Oh pasti Dinda jarang nongkrong ya, banyak tugas dari } \\
\text { dosen atau bikin makalah." }\end{array}$ \\
\hline 4 & $\begin{array}{l}\text { "Ian, pintu kamar adik lo udah punya pacar belum? Ada yang } \\
\text { naksir tuh, dari tadi diliatin mulu.," Riani buka kata. } \\
\text { "Yo'i ada yang seneng sama kayu jati," timpal Ian. }\end{array}$ \\
\hline 5 & $\begin{array}{l}\text { "Berapa meter tingginya, Ta?" } \\
\text { "3676m dari permukaan laut." } \\
\text { "Busyet, tinggi juga ya," Zafran kaget sendiri. } \\
\text { "Tinggi banget." Riani bengong, } \\
\text { "Medannya berat nggak, Ta?" } \\
\text { "Ya, lumayan." } \\
\text { "Kuat apa kita? Bawa paus lagi??" Zafran bercanda sambil } \\
\text { menendang Ian pelan di dengkulnya. }\end{array}$ \\
\hline
\end{tabular}




\begin{tabular}{|c|c|}
\hline 6 & $\begin{array}{l}\text { "Minggu-minggu depan ada apa lagi, Man?" } \\
\text { "Ada gathering di Puncak, outing, sama dua kegiatan } \\
\text { launching. Minggu-minggu depan kita hanya ada empat acara." } \\
\text { "Tambah satu lagi.., tapi akhir Agustus." } \\
\text { "Haah? Lo dapet dari mana lagi?" Firman berteriak senang. } \\
\text { "Tadi waktu penutupan tiba-tiba ada yang nawarin pameran } \\
\text { persis kayak gini, tapi di Bandung." } \\
\text { "Nggak ada yang nolak, Ta?" Genta menggeleng. }\end{array}$ \\
\hline 7 & $\begin{array}{l}\text { "Mas ada api?" tanya laki-laki itu lagi. } \\
\text { "Ada...'?" jawab Ian sambil merogoh sakunya dan } \\
\text { mengeluarkan korek gas. }\end{array}$ \\
\hline 8 & $\begin{array}{l}\text { "Tapi gue yakin, pasti ada sesuatu yang pasti...yang nggak bisa } \\
\text { ditawar, yang bahkan Albert Einsten nggak bisa jelasin." } \\
\text { Semua anak manusia itu melihat ke langit biru di atas Ranu } \\
\text { Kumbolo. Tersenyum satu sama lain. } \\
\text { "Iya, yang di atas sana itu satu yang pasti." }\end{array}$ \\
\hline 9 & $\begin{array}{l}\text { "Genta bengong mulu nih. ," tiba-tiba Riani nyeletuk sambil } \\
\text { memukul lembut dengkul Genta. Nggak tau aja lo, kata Genta } \\
\text { dalam hati. } \\
\text { "Makanya jangan ngomongin kerjaan kalo malam Minggu. Kan } \\
\text { waktu itu kita udah janji." Arial nyambung. } \\
\text { "Lo jadi make gue kan Senin, Ta?" tanya Arial sekaligus } \\
\text { memberi tip ex sama yang baru dia omongin. }\end{array}$ \\
\hline 10 & $\begin{array}{l}\text { Seorang penumpang bertanya ke Zafran, "Mas ada yang ulang } \\
\text { tahun ya?" } \\
\text { "Nggak, Pak! Itu ada yang baru diterima kerja jadi pesut di } \\
\text { Ancol," kata } \\
\text { Zafran sambil menunjuk Ian. }\end{array}$ \\
\hline
\end{tabular}

\begin{tabular}{|c|c|}
\hline 11 & $\begin{array}{l}\text { Arial memberanikan diri bertanya,"Napa Mas?"(Ada apa } \\
\text { Mas?) "Iku...wong papat masak rong puluh." (Itu...empat orang } \\
\text { masak dua puluh) Lehernya bergerak pelan menunjuk ke arah } \\
\text { petugas di kejauhan. "Kenapa nggak beli di stasiun, Mas?" } \\
\text { "Yo...biasane yo ora ana petugase. Iki lagi sial wae." } \\
\text { (Ya...biasanya ya nggak ada petugas. Ini sedang sial saja.) } \\
\text { "Tapi bukannya kalo naik kereta emang harus beli karcis, } \\
\text { Mas?" }\end{array}$ \\
\hline 12 & $\begin{array}{l}\text { "Abis dari mana?" Dinda bertanya. } \\
\text { "Ngerokok di pintu gerbong," jawab Zafran. "Oh..." } \\
\text { "Saya perkenalkan guru filsafat saya, Socrates yang bijak," } \\
\text { Genta menunjuk Zafran yang senyum-senyum. } \\
\text { "Terima kasih Plato, muridku yang baik." }\end{array}$ \\
\hline
\end{tabular}

\section{PEMBAHASAN}

\section{Implikatur Non-Konvensional}

Implikatur non-konvensional merupakan implikasi pragmatik yang tersirat di dalam suatu uajran. Berikut ini akan dipaparkan hasil analisis data/temuan penelitian pada novel $5 \mathrm{~cm}$ karya Donny Dhirgantoro terkait implikatur nonkonvensional.

\section{Data (1)}

“Ada nyokap lo nggak?" Zafran sok basa-basi. "Ada adik gue Lo mau?" jawab Arial.

Implikatur non-konvensional yang diucapkan oleh Zafran "Ada nyokap lo nggak?" merupakan bentuk tuturan tidak 
langsung. Tuturan tersebut sengaja diucapkan untuk menyamarkan maksud Zafran. Namun, pada konteks tuturan bersama Arial, pernyataan tersebut telah dipahami oleh lawan tutur. Fokus pada jawaban Arial ialah memastikan yang dimaksud oleh Zafran ialah ada atau tidaknya adik dari Arial.

\section{Data (2)}

"Ada yang mau Indomie nggak?" Arial menawari tem temannya.

Semua menggeleng kecuali Ian.

“Pake telornya dua yaa...," Ian teriak.

Dari tuturan data di atas menjelasakan bahwa keinginan Ian dibuatkan Indomie dengan ditambahkan telur sejumlah 2 butir. Yang terlihat pada tuturan hanya kalimat “Pake telornya dua yaa...,". Hal tersebut guna menjawab pertanyaan tawaran dari Arial.

\section{Data (3)}

"Kalo dikampus nongkrongnya di mana?" "Nggak nongkrong."

"Oh pasti Dinda jarang nongkrong ya, banyak tugas dosen atau bikin makalah."

Dari tuturan data di atas menjelasakan bahwa pada kalimat "Nggak nongkrong." sesungguhnya yang dimaksud dengan nongkrong ialah kumpul bersama temanteman dan menghabiskan waktu sembari bersantai.

\section{Data (4) \\ "Ian, pintu kamar adik lo udah punya pacar belum? Ada yang naksir tuh, dari tadi diliatin mulu,." Riani buka kata. "Yo"i ada yang seneng sama kayu jati," timpal Ian.}

Maksud kayu jati disini memiliki makna tersirat yaitu Dinda diibaratkan kayu jati karena Zafran selalu melihat kamar Dinda, sembari berharap Dinda keluar.

\section{Data (5)}

"Berapa meter tingginya, Ta?"
"3676m dari permukaan laut."
"Busyet, tinggi juga ya," Zafran kaget sendiri.
"Tinggi banget." Riani bengong,
"Medannya berat nggak, Ta?"
"Ya, lumayan."
"Kuat apa kita? Bawa paus lagi?" Zafran bercanda sambil menendang Ian pelan di dengkulnya.

Pernyataan di atas mengimplikasikan makna tersirat yang disampaikan oleh mitra tutur bahwa secara tidak langsung sebelumnya mereka sudah memahami maksud tuturan. 


\section{Data (6)}

"Minggu-minggu depan ada apa lagi, Man?"

“Ada gathering di Puncak, outing, sama dua kegiatan

launching. Minggu-minggu depan kita hanya ada empat acara.

"Tambah satu lagi..., tapi akhir Agustus."

"Haah? Lo dapet dari mana lagi?" Firman berteriak senang.

"Tadi waktu penutupan tiba-tiba ada yang nawarin pameran persis kayak gini, tapi di Bandung. "

"Nggak ada yang nolak, Ta?" Genta menggeleng.

Berdasarkan dialog di atas diketahu bahwa para peserta tutur telah mengetahui bersama apa yang dimaksud dari tuturan mereka, yaitu mereka sedang membahas seputar event organizing. Berdasarkan fakta tersebut, maka dapat disimpulkan bahwa konteks fisik yang terdapat pada data tersebut adalah di sebuah tempat yang digunakan untuk acara event organizing (pameran) mereka.

\section{Data (7)}

"Mas ada api?" tanya laki-laki itu lagi.

“Ada...!' jawab Ian sambil merogoh sakunya dan mengeluarkan korek gas.

Konteks epistemik, ketika laki-laki bertanya kepada laki-laki lain "Ada api?", pasti yang dimaksudkan adalah korek api, karena laki- laki identik dengan kebiasaan merokok.

\section{Data (8)}

"Tapi gue yakin, pasti ada sesuatu yang pasti...yang nggak bisa ditawar, yang bahkan Albert Einsten nggak bisa jelasin."

Semua anak manusia itu melihat ke langit biru di atas Ranu Kumbolo. Tersenyum satu sama lain.

"Iya, yang di atas sana itu satu yang pasti."

Konteks epistemik pada data tersebut adalah Tuhan merupakan satu zat yang pasti. Meskipun Einstein telah membuktikan bahwa tidak ada suatu hal yang pasti dengan teori relativitasnya, namun Tuhan adalah satu hal yang pasti yang bahkan Einstein pun tidak bisa menjelaskan.

\section{Data (9)}

\author{
"Genta bengong mulu nih., ," tiba-tiba Riani nyeletuk sambil \\ memukul lembut dengkul Genta. Nggak tau aja lo, kata Genta \\ dalam hati. \\ "Makanya jangan ngomongin kerjaan kalo malam Minggu. Kan \\ waktu itu kita udah janji." Arial nyambung. \\ "Lo jadi make gue kan Senin, Ta?" tanya Arial sekaligus \\ memberi tip ex sama yang baru dia omongin.
}

Tokoh yang berbicara dalam data tersebut adalah Riani. Lawan tuturnya dalam percakapan tersebut adalah Arial, sedangkan objek tuturnya adalah Genta. Hubungan antara Riani dan Arial, keduanya merupakan sahabat satu geng. Hubungan antara Riani dan Arial dengan Genta (objek tutur) adalah 
teman dekat (sahabat) yang biasanya diajak Genta untuk berpartisipasi dalam proyeknya.

\section{Data (10)}

Seorang penumpang bertanya ke Zafran, "Mas ada yang ulang tahun ya?"

"Nggak, Pak! Itu ada yang baru diterima kerja jadi pesut di Ancol, "kata

Zafran sambil menunjuk Ian.

Dalam tuturan di atas, dapat dipahami bahwa konteks pembicara antara Zafran dan seseorang yang bertanya kepadanya berkaitan tentang suasanya disekitar mereka. Penanya bermaksud mendapat penjelasan dari Zafran terkait kejadian apa yang tengah berlangsung.

\section{Data (11)}

Arial memberanikan diri bertanya,"Napa Mas?"(Ada apa Mas?) "Iku...wong papat masak rong puluh." (Itu...empat orang masak dua puluh) Lehernya bergerak pelan menunjuk ke arah petugas di kejauhan. "Kenapa nggak beli di stasiun, Mas?"

"Yo... biasane yo ora ana petugase. Iki lagi sial wae."

(Ya...biasanya ya nggak ada petugas. Ini sedang sial saja.) "Tapi bukannya kalo naik kereta emang harus beli karcis, Mas?"

Tokoh yang berbicara dalam data tersebut adalah Arial, lawan tuturnya adalah penumpang lain, dan objek tuturnya adalah tiket kereta. Hubungan antara Arial dan penumpang tersebut adalah sama-sama penumpang kereta api yang dikenakan kewajiban membayar tiket ketika menggunakan fasilitas umum tersebut.

\section{Data (12)}

"Abis dari mana?" Dinda bertanya.

"Ngerokok di pintu gerbong," jawab Zafran. "Oh..."

"Saya perkenalkan guru filsafat saya, Socrates yang bijak," Genta menumjuk Zafran yang senyum-senyum.

"Terima kasih Plato, muridku yang baik."

Inferensi yang muncul dari analisis konteks tersebut menunjuk pada implikatur bahwa Genta mencoba memberitahukan pada teman- temannya kalau ia dan Zafran ketika merokok tadi telah membicarakan banyak hal mengenai filsafat yang diajarkan oleh Socrates. Respon Zafran yang menyebut Genta sebagai "Plato" merupakan perumpamaan, karena sebelumnya Genta telah banyak mendengarkan seperti murid mendengarkan ceramah gurunya. Jadi, maksud dari implikatur tersebut adalah untuk memuji Zafran.

\section{PENUTUP}

Bahasa sebagai sarana komunikasi antar masyrakat dalam pengucapannya 
memiliki makna-makna yang pemahamannya tidak dapat melihat dari teks kalimat yang diucapkan itu saja, melainkan harus mengaitkan dengan konteks percakapan. Konteks memiliki peran terpenting dalam implikatur percakapan karena dengan memahami konteks dapat melatarbelakangi dari tuturan komunikasi itu. Artinya, konteks dalam percakapan apapun, antara penutur dan lawan tutur memiliki pemahaman yang sama mengenai tema yang dibicarakan. Bahkan, dalam implikatur percakapan hanya penutur dan lawan tutur saja yang mengetahui konteks pembicaraan itu.

Hal ini terjadi karena masyarakat ingin menyamarkan makna tersebut. Hal yang demikian disebut dengan implikatur nonkonvensional.

Begitu juga halnya dalam penelitian ini terdapat implikatur nonkonvensional pada percakapan tokoh yang ada di dalam Novel 5 cm karya Donny Dhirgantoro.

Data yang ditemukan pada novel tersebut juga memiliki kesamaan makna tentang implikatur nonkonvensional yaitu semua tokoh dalam percakapannya menyamarkan sesuatu agar berbeda dengan yang sebenarnya dari apa yang diucapkan.

\section{DAFTAR RUJUKAN}

Kuntarto, Eko dan Gafar, Abdoel. 2016. Manifestasi Prinsip Kesantunan, Prinsip Kerja Sama, dan Implikatur Percakapan pada Interaksi Di Lingkungan Sekolah. Jurnal Ilmiah Universitas Batanghari Jambi Vol.16 No.3 Tahun 2016. Jambi: Univeritas Batang Hari.

Irawan, W.D. (2019). Kata Sapaan Kekerabatan dalam Masyarakat Lampung Sungkai.Edukasi Lingua Sastra, 17 (1), 96-101.

Rusminto, Nurlaksana Eko. 2010. Memahami Bahasa Anak-anak:

Sebuah Kajian Analisis Wacana Panduan Bagi Guru, Orang Tua dan Mahasiswa Jurusan Bahasa. Bandar Lampung: Universitas Lampung.

Sudaryanto. 2016. Metode Penelitian Pendidikan. Jakarta: Kencana. 